\section{La comprensión hegeliana del delito}

The Hegelian Understanding of Crime

\author{
Esteban Mizrahi
}

\section{RESUMEN}

En el presente trabajo se argumenta que la comprensión hegeliana del delito en la Filosofía del derecho (1821) tiene tres momentos diferenciados y complementarios. En el primero, se define al delito en su concepto con total independencia de lo establecido por la ley positiva; en términos objetivos, el delito puede ser interpretado como un juicio contradictorio en la medida en que niega aquello que afirma: el valor de la persona. En el segundo, se explica por qué una acción delictiva es imputable a un sujeto; en términos subjetivos, el delito es una acción que ha de poder ser imputada a un actor y para ello el agente debe ser consciente de su acto y éste responder a su propósito. En el tercero, se considera la acción criminal a partir de su peligrosidad social; en términos de la eticidad, el delito implica no sólo violencia sino defraudar y poner en tela de juicio las expectativas sociales depositadas en el cumplimiento de las normas vigentes en el Estado.

Palabras clave: delito; derecho; Estado; Hegel; imputación

\section{ABSTRACT}

This paper presents the Hegelian understanding of crime in the Philosophy of Right (1821), according to which there are three differentiated and complementary moments. In the first one, the crime is defined in its concept with total independence from what is established by positive law. The crime can be interpreted in objective terms as a contradictory judgment insofar as it denies what it affirms: the value of the person. In the second one, it is explained why a criminal action is attributable to a subject. The crime is in subjective terms an action that must be imputed to an actor and to this extent the agent must be aware of their act and this act must respond to their purpose. In the third one, criminal action is considered based on its social dangerousness. The crime involves, in terms of ethics, not only violence but also defrauding and questioning the social expectations placed on compliance with the State regulations in force.

Keywords: crime; law; state; Hegel; imputation
INFORMACIÓN

https://doi.org/10.46652/resistances.v2i4.63 ISSN $2737-6222$ |

Vol. 2 No. 4, 2021, e21063

Quito, Ecuador

Enviado: octubre 16, 2021

Aceptado: diciembre 04, 2021

Publicado: diciembre 10, 2021

Publicación continua

Sección dossier | Peer Reviewed

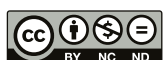

open $\bigcirc$ access

AUTOR

Esteban Mizrahi

Universidad Nacional de La Matanza - Argentina

emizrahi@unlam.edu.ar

Conflicto de intereses

El autor declara que no existe conflicto de interés posible.

Financiamiento

Institución patrocinadora: Foncyt Universidad de Buenos Aires (UBA). Nombre de proyecto: Los fundamentos modernos del Derecho penal contemporáneo. Estado Derecho y pena de Hobbes a Hegel. Número de proyecto: PICT-2019-2019-04071 Agradecimiento N/A

Nota

artículo no se desprende de un trabajo anterior.
PUBLISHER 


\section{Introducción}

¿Existe algún criterio racional en función del cual sea posible determinar qué tipo de acciones son en sí mismas punibles? Si lo hubiera, sería de mayor utilidad para examinar la eventual racionalidad de un ordenamiento jurídico que para operar en él. Por lo general, se entiende que una actividad configura un delito, cuando el Estado la declara socialmente inaceptable e instruye a sus ciudadanos para que no la practiquen, advirtiéndoles que, de hacerlo, pueden ser condenados y castigados dentro de los límites especificados por la ley (Simester \& Von Hirsch, 2011). Además, el Estado se compromete a imponerles penas apropiadas dentro de un rango que refleje la culpabilidad de la conducta probada en debido proceso. Por esta razón, en los manuales de derecho penal suele plantearse que la tipicidad, antijuricidad y culpabilidad son criterios válidos y suficientes para analizar si la conducta de un sujeto configura delito; esto es: si esa acción está prevista en el código penal, si con ella se contradice al ordenamiento jurídico vigente y si, finalmente, es imputable al sujeto en cuestión. Sin embargo, esta perspectiva no explica las razones por la cuales un determinado ordenamiento jurídico criminaliza tal o cual conducta ni tampoco invoca un criterio general con el cual pueda determinarse si ciertas actividades son en sí mismas punibles y que sólo por ello está justificada su criminalización. Simplemente, se asume que los tipos penales vigentes en un Estado son válidos sin evaluar la racionalidad de sus determinaciones. De ahí que un jurista clásico del derecho penal alemán, como Edmund Metzger, afirme que la tipicidad constituye la ratio essendi de la antijuricidad de una acción (Metzger, 1949, \$22, I). Esto implica aseverar que una conducta es antijurídica básicamente porque está tipificada como tal y que esa es la única razón por la cual constituye un delito.

Por el contrario, lo que guía el planteo hegeliano en la Filosofía del derecho (1821) y en sus lecciones previas y posteriores sobre la materia es, primero, definir al delito en su concepto con total independencia y anterioridad a lo establecido por la ley positiva para, en segundo lugar, explicar las razones por la cuales una acción delictiva es imputable a un sujeto y, por último, considerar la peligrosidad social de la acción criminal en el marco del derecho positivo vigente en un Estado. Para Hegel, el delito implica problemáticas diversas según la esfera discursiva en que se presenta Así, en el "Derecho abstracto" se explican las condiciones bajo las cuales es posible la emergencia del delito, se precisan sus características definitorias y la necesidad de su superación a través de la pena. En la "Moralidad" se analiza la estructura de la acción que permite imputar responsabilidad a un sujeto por lo que hace. Finalmente, en la "Eticidad" se discute el grado de severidad de las penas en relación con la peligrosidad social del delito. En la filosofía del derecho hegeliana estas tres esferas discursivas no constituyen compartimentos estancos, sino que son momentos articulados de un método expositivo, que Hegel denomina "científico" (GW 14.1, Vorr.: 6), con el cual se presentan las categorías jurídicas según una lógica argumental que exhibe la necesidad interna de su encadenamiento. En este marco, no sólo la pena encuentra su justificación, sino que también el delito se manifiesta como una determinación necesaria para que el derecho de las personas como propietarios, reconocido en la figura del contrato, deje de estar meramente presupuesto y cobre fuerza de ley. En tal sentido, la comprensión hegeliana del delito permite pensar la naturaleza de la acción criminal y algunas de sus consecuencias más allá de los procedimientos establecidos por el Estado para criminalizar determinados conductas. 


\section{El delito en el "Derecho abstracto"}

En el "Derecho abstracto" Hegel lleva a cabo un análisis de las categorías jurídicas centrales del derecho privado moderno, de sus presupuestos y condiciones de posibilidad, con independencia de las circunstancias históricas, culturales y políticas en que ellas se han ido configurando. De ahí que la categoría de persona no remita a un individuo asocial que se vincula con las cosas y con los demás en estado de naturaleza sino a uno plenamente socializado en el marco de las instituciones propias de un mundo ético, pero haciendo abstracción de este plexo de relaciones que le dan sustento a su individualidad. Para exponer y analizar este entramado jurídico ya configurado, Hegel asume como punto de partida aquella unidad que constituye su condición primera, a saber: la voluntad libre en la determinación de la inmediatez. Se trata de la voluntad individual de un sujeto que se refiere a sí mismo y se comporta de manera negativa frente a lo existente (GW $14.1, \S 34$, p. 51). Con esto se quiere decir que la conciencia es capaz, mediante su autorreferencia, de elevarse como puro yo por sobre los impulsos, las necesidades y las circunstancias que la involucran en tanto individualidad. Precisamente, en esta relación de la conciencia consigo misma como yo indeterminado radica su universalidad. Se trata de una mera relación formal en la que "no hay ninguna diferencia entre la voluntad y su contenido" (GW 26.2, §34, p. 808). Por ello constituye el fundamento de la categoría de persona. No es que el sujeto de una acción no esté condicionado por las circunstancias, no tenga deseos, impulsos o necesidades. Todo esto sucede. Pero se es persona sólo en la medida en que subsiste la posibilidad de no dejarse determinar por ninguno de estos factores. Una persona ha de poder depender de sí misma para determinarse en la acción y por ello esta categoría es el fundamento de toda determinación jurídica posterior.

Desde la perspectiva del sistema hegeliano, el espíritu libre deja la esfera de la subjetividad e ingresa en la objetividad con la categoría de persona. Ser persona implica un aspecto realizativo vinculado tanto con la exigencia de individuación como con la necesidad de reconocimiento intersubjetivo. El espíritu libre se singulariza como individualidad cuando es persona. Pero este movimiento se produce primero según el modo de la inmediatez, por lo cual la individualidad es la certeza de la voluntad que se sabe a sí misma como unidad autoconsciente del yo, absolutamente libre para actuar. Se trata de la conciencia típicamente moderna de la libertad de acción como arbitrio, según la cual la subjetividad está capacitada para aceptar o rechazar una determinada acción o norma para actuar. Pero un individuo es sujeto de derecho sólo si es capaz de reconocerse a sí mismo como persona al reconocer a los otros como portadores de derechos. Ello se evidencia en que carece de todo sentido elevar una pretensión normativa sobre una cosa, si ese acto no está dirigido a otro ser capaz de hacer lo mismo. Por esta razón, sólo llega a ser persona para sí mismo quien es reconocido por otro como persona y en esa intrínseca reciprocidad, la voluntad libre como sujeto se tiene a sí misma por objeto. De ahí que la idea de una persona sola o única sea una contradicción en si misma (Jakobs, 2008). La persona se constituye a partir del reconocimiento recíproco. Con la categoría de persona propia del derecho moderno se expresa el reconocimiento de la libertad de la voluntad.

Con todo, la voluntad libre necesita manifestarse en algo exterior para ser real: "La persona, para existir como idea, tiene que darse una esfera exterior para su libertad” (GW 14.1, §41, p. 55). Esto tiene lugar, primero, a través de las diversas formas de toma de posesión y luego en la relación 
de propiedad reconocida con la celebración de contratos. Sin embargo, esta exterioridad que las cosas y el propio cuerpo le ofrecen a la voluntad libre para manifestarse también la condicionan y la someten a una necesidad. Así, con la esfera exterior requerida para su existencia queda habilitada también su vulnerabilidad. Ciertamente, "la voluntad libre en y para sí no puede ser coaccionada” (GW 14.1, §91, p. 88); pero sí puede serlo en cuanto está depositada en una cosa o en la corporalidad.

Por este motivo, Hegel comienza el tratamiento del delito en el "Derecho abstracto" señalando que una condición para el ejercicio de coacción (Zwang) es, precisamente, que la voluntad libre se exteriorice en la propiedad y en la corporalidad. Sin esta manifestación, el individuo no existe como persona. Pero al hacerlo no puede evitar someterse a los condicionamientos de los otros ni a exponerse a prácticas de coacción. Aun así, ser violentado, sometido o sojuzgado también depende de la permanencia de la voluntad en una esfera exterior de la que puede retraerse o retirarse, como bien observaron los estoicos en la antigüedad. Por ello, Hegel sentencia provocativamente que "sólo puede ser forzado a algo quien quiera dejarse forzar" (GW 14.1, §91, p. 88). Con esto último se expresa la tensión constitutiva del ámbito jurídico implícita en la categoría de persona, a saber, que la objetividad ofrece una esfera exterior para la realización de la libertad que conlleva de manera necesaria aceptar voluntariamente la posibilidad de coaccionar o ser coaccionado. De ahí que quien es persona no pueda eludir la atribución de responsabilidad pues la existencia exterior de la voluntad no es un hecho natural ni compulsivo sino una operación consciente. De ello se sigue, según Hegel, que tanto el ilícito en general como el delito en particular constituyen determinaciones jurídicas necesarias y no meras posibilidades contingentes. El derecho es un ordenamiento coactivo precisamente porque la coacción constituye un presupuesto necesario cuando la libertad de la voluntad se realiza en una esfera exterior.

Hegel sostiene que, en términos lógicos, el delito es equiparable a un juicio negativo infinito que encierra el contrasentido de evitar la determinación del sujeto en el predicado, es decir, aquello en que propiamente consiste un juicio. En la Ciencia de la lógica ofrece algunos ejemplos: "la rosa no es un elefante, el entendimiento no es una mesa” y afirma también que el "ejemplo más real es la mala acción” (WL, II, pp. 69-70). Por tal motivo, las acciones que merecen sanción penal son aquellas con las que se niega en el predicado no sólo la particularidad del contenido sino también toda su extensión, es decir, su universalidad (GW 14.1, §95, p. 89). En este caso, la universalidad de la persona, el derecho en cuanto tal.

A partir de estos elementos, Hegel define al delito como una acción que "en cuanto exteriorización de una voluntad, suprime la existencia o exteriorización de una voluntad” (GW 14.1, §92, p. 88), negando así sus propias condiciones de posibilidad. Tanto para cometer un delito como para padecerlo, hay que ser persona porque sin el reconocimiento recíproco de capacidad jurídica $y$, en consecuencia, del derecho a elevar pretensiones normativas sobre las cosas y la propia corporalidad no hay espacio conceptual para el delito. En el reino natural existen fuerzas contrapuestas y seres vivos que mutilan o les quitan la vida a otros, pero esas acciones no son delictivas porque no implican la violación de derechos previamente reconocidos. Por el contrario, quien comete un delito reconoce al otro como titular de derechos y lo desconoce en la misma medida. De ahí que la acción criminal pueda ser interpretada como un juicio contradictorio. En el robo, por ejemplo, el actor reconoce a su víctima como dueño de la cosa y al mismo tiempo no 
lo hace porque se apodera del objeto sin el consentimiento del dueño. Pero hay robo sólo en la medida en que también el actor es portador de capacidad jurídica. El delito refiere, entonces, a una acción con la cual se niega aquello que necesariamente se presupone, a saber, la condición de persona tanto del actor como de la víctima. En esta caracterización hegeliana del delito se exhibe con toda claridad la clausura operativa del derecho como subsistema social (Luhmann, 1995), pues solo tienen carácter jurídico aquellas acciones que son imputables a sujetos de derecho. En esta circularidad queda excluida toda posible lesión del orden normativo por agentes externos al propio sistema. Por eso Hegel afirma que "la acontecida lesión del derecho en cuanto derecho tiene por cierto una existencia positiva exterior, pero esta es en sí nula” (GW 14.1, §97, p. 90). Su nulidad radica en que la acción criminal conlleva la pretensión de eliminar el derecho cuya existencia misma presupone y confirma.

La tensión entre la universalidad de la categoría de persona y la individualidad, en la que se singulariza y cobra existencia, puede ser entendida mediante una analogía con el proceder de las matemáticas, pese a que Hegel rebaje esta manera de pensar a una forma de mala infinitud. El resultado de un cálculo es independiente del agente que calcula. Si nadie realiza la operación, el cálculo no tiene lugar. Pero si alguien lo hace, el resultado correcto no depende de quien lleva a cabo la operación ni de su acierto o error al momento de calcular. Un error en la operación impide llegar al resultado correcto, pero no lo pone en tela de juicio ni impugna la exactitud de las matemáticas como ciencia. De modo semejante, la universalidad de la voluntad, que constituye el fundamento de la categoría de persona, no puede ser impugnada por una subjetividad individual mediante una acción criminal.

Este aspecto ya había sido trabajado por Hegel en el Sistema de la eticidad de la época de Jena (1802-1803). En la segunda parte de este ensayo explica que cuando el actor de un hecho criminal cree que el peso de su acción recae sólo sobre su víctima como un ser ajeno y aparentemente exterior a él, también se lesiona a sí mismo de un modo ideal. De esta manera, la acción delictiva manifiesta que,

...el acto exterior es al mismo tiempo un acto interior, el delito cometido a un extraño, también se lo ha cometido a sí mismo. Pero la conciencia (Bewußtsein) de la propia aniquilación es una conciencia subjetiva (Gewissen), interior, o la mala conciencia (böse Gewissen). De esta manera, es incompleta y debe exhibirse también exteriormente como justicia vengadora. Porque es algo interior e incompleto tiende a una totalidad (SS, p. 41).

Esta es la razón por la cual el castigo bajo la forma de la venganza o de la pena también tiene como función recomponer la totalidad desgarrada en el seno de la subjetividad criminal articulando la voluntad individual, interior y subjetiva con su configuración exterior, objetiva y universal.

Pero esto último no procede a través de la reforma de la subjetividad criminal porque eso es algo que sólo puede tener lugar en el ámbito de la interioridad y, por tanto, excede la esfera de lo estrictamente jurídico. Antes bien, el actor ha de ser considerado como un ser racional. Hegel observa que con la pena se le inflige al delincuente un castigo que "en tanto justo es al mismo 
tiempo su voluntad existente en sí, una existencia de su libertad, su derecho; por lo tanto, es un derecho en el delincuente mismo, es decir, puesto en su voluntad existente, en su acción" (GW 14.1, $\S 100$, p. 92). Pero esto no significa que la pena encuentre allí su justificación. Para Hegel la pena sólo exhibe la nulidad del acto delictivo: "La manifestación de esta nulidad suya es la aniquilación de la lesión, que también entra en la existencia - la realidad efectiva del derecho, su necesidad mediada consigo misma mediante la supresión de su lesión" (GW 14.1, §97, p. 90). La pena se sitúa, entonces, en el mismo plano que el delito, a saber, en la esfera de exterioridad de la voluntad. Allí se ha dejado de reconocer la universalidad de la persona con el hecho criminal y es allí donde tiene que ser restituida la validez del derecho (GW 26.1, §46, p. 47).

Desde sus Lecciones sobre filosofía del derecho de la época de Heidelberg (1817-1818) y hasta la publicación de la Enciclopedia de Berlín (1830), Hegel considera que la necesidad de conciliar la universalidad de la voluntad con su particularidad, cuyo conflicto se expresa con el delito y la pena, introduce la problemática de la "Moralidad" (Moralität) y no inmediatamente la del Estado como órgano encargado de la ejecución penal. La esfera de la "Moralidad" se presenta como una instancia mediadora que permite elaborar la tensión entre estas dos determinaciones contrapuestas de la voluntad cuya unidad contingente toma la forma de voluntad común en la figura del contrato. Esta unidad es contingente porque se introduce en la realidad mediante la voluntad subjetiva de los particulares. Por esta razón, el reconocimiento intersubjetivo también es sólo aparente:

...este primer ser reconocido es contingente, porque la voluntad subjetiva no se ha puesto todavía como idéntica con la voluntad universal, y no ha reconocido aún la voluntad particular como una voluntad diferenciada. El derecho tiene su realidad efectiva sólo mediante la voluntad subjetiva y el derecho es así contingente (GW $26.1, \S 49$, p. 53).

Precisamente, la insuficiencia del "Derecho abstracto" radica en el carácter contingente del reconocimiento intersubjetivo objetivado en el contrato a través de la voluntad común de la partes. Esto conduce a diversas formas de negación del derecho, entre las cuales la más radical es el delito. Sin embargo, no es posible superar el delito en esta esfera discursiva pues el castigo asume aquí la forma también contingente de la venganza que no atiende al valor como igualdad intrínseca entre las acciones de delinquir y castigar. Para que la pena sustituya a la venganza en el ejercicio del castigo es necesario que el derecho presupuesto y abstracto valga como derecho positivo vigente en un Estado. De ahí que únicamente con la "Eticidad", cuando la voluntad individual quiere lo universal y lo universal se realiza como voluntad subjetiva, la categoría de persona cobra validez efectiva y su negación puede ser exhibida también como nula con la sanción penal de un delito.

Pero si el derecho de la objetividad de la voluntad se reafirma con el castigo y la pena, el derecho de la subjetividad se realiza en la elección del propósito con que se lleva a cabo una acción, incluso la acción de delinquir: "El punto de vista moral es, por tanto, la figura del derecho de la voluntad subjetiva. Según este derecho, la voluntad es y reconoce sólo aquello que es suyo, es decir, lo que existe en ella como algo subjetivo" (GW 14.1, §107, p. 100). Este derecho de la subjetividad se opone al de la objetividad como algo interior contrapuesto a lo exterior. En este sentido, la perspectiva moral se expresa en el derecho subjetivo a reconocer en la acción sólo aquello que responde al propósito del sujeto. 


\section{La imputación de un delito en la "Moralidad"}

En la "Moralidad" Hegel analiza las condiciones bajo las cuales es posible atribuirle a un sujeto una acción como suya, es decir, cuáles son los presupuestos necesarios para la imputación. En este contexto, el derecho de la subjetividad de la voluntad se expresa como el saber del agente respecto de su hacer. En el caso de un delito, por ejemplo, sólo es posible atribuirle responsabilidad al actor de un hecho criminal si sabe lo que está haciendo. Un hecho puede ser imputado como responsabilidad de la voluntad sólo si el agente está en condiciones de reconocer la acción como suya, es decir, de reconocer en el hecho aquello que ya estaba presupuesto en su propósito. A esto Hegel lo denomina “el derecho del saber" (GW 14.1, §117, p. 105).

Pero el estado de conocimiento del agente de una acción no sólo determina su grado de responsabilidad respecto del hecho sino también el significado de la acción misma. Así un mismo hecho puede describirse de manera distinta dependiendo de la conciencia de su agente. Por un lado, un determinado estado de cosas que se sucede a otro está relacionado con el obrar de un agente si algo de lo que este hizo o dejó de hacer es presupuesto necesario para la configuración del estado resultante. Por el otro, tanto la descripción de la acción como del hecho dependen esencialmente del saber que tiene el sujeto acerca de lo que hace (Ormeño Karzulovic, 2020). Hegel lo expresa en estos términos:

La voluntad que por sí misma actúa y que dirige sus fines hacia una existencia previamente dada, tiene una representación de las circunstancias en que aquélla se encuentra. Pero puesto que por esta presuposición la voluntad es finita, el fenómeno que se muestra en el objeto es para ella contingente, y puede contener algo distinto de su representación (GW 14.1, §117, p. 105).

Por tanto, si el resultado de la acción concuerda en términos generales con la representación de las circunstancias en que esta tiene lugar es posible imputar responsabilidad al actor por el hecho; de lo contrario, no.

En tal sentido, puede afirmarse que un hecho como la pérdida de la vida de un ser humano a manos de otro constituye un homicidio (y no un accidente desafortunado) sólo si el resultado responde al propósito del autor y el medio utilizado es idóneo para la comisión de ese fin en relación con la representación de las circunstancias. En lo que se refiere a lo primero podría mencionarse el caso de una madre que frente a un cuadro febril de su hijo le suministra un analgésico a base de ácido acetilsalicílico. Esta acción puede causar en quien recibe la medicación inflamación de órganos como el hígado o el cerebro e incluso provocar la muerte si se administra en el curso de enfermedades virales como varicela o gripe. Naturalmente, una madre no tiene por qué conocer este efecto adverso de la aspirina que la medicina describe como síndrome de Reye. Por esta razón, su acción no puede ser calificada como tentativa de homicidio agravado por el vínculo, aun cuando llegado el caso fuera un presupuesto necesario y determinante para desencadenar la muerte del hijo. En lo que concierne a lo segundo, es decir, a la elección de un medio idóneo para la producción de un resultado, debe observarse que eso no depende sólo de la obtención del resultado mismo sino, ante todo, de la representación general de las circunstancias y las relaciones causales entre las cosas del mundo externo. Un ejemplo de esto último podría ser 
el siguiente: Un individuo se propone quitarle la vida a otro. A tal efecto deja escapar de su mano una pluma de ganso que llevada por el viento unos trescientos metros termina por dar en el ojo de su víctima justo cuando se encuentra cruzando la calle. Esto ocasiona que el sujeto no pueda evitar ser arrollado por un automóvil, hecho que provoca su muerte inmediata. También en este caso, la acción del autor constituye un presupuesto necesario para la producción del resultado, sin embargo, el medio utilizado es tan poco idóneo que no es posible atribuirle responsabilidad alguna al agente en el desenlace de los acontecimientos. El resultado es más una obra del azar que un efecto necesario de su propia acción.

Desde luego, como la acción siempre tiene lugar en el ámbito de la exterioridad, donde las circunstancias son complejas y cambiantes, también el acto de dejar caer una cerilla encendida en un granero donde duerme una persona podría constituir un medio idóneo para provocar un incendio o no. Ello depende de cómo están configuradas las circunstancias según una pluralidad de relaciones causales que el autor, por lo general, no conoce exhaustivamente. Al respecto, Hegel señala que siempre es posible aducir esta o aquella circunstancia:

...por ejemplo, en caso de un incendio provocado que el fuego no prendió; o, por otro lado, que el asunto fue más allá de lo que el autor se proponía. No se puede hacer esta distinción entre buena o mala suerte porque el hombre cuando actúa sabe que se entrega a la exterioridad, un terreno sobre el que ya no tiene poder (GW 26.2, §119, p. 877).

El autor sabe que en esa exterioridad no todo lo que sucede responde a su propósito ni se corresponde con su saber. Por tal motivo, con el propósito y la elección de un medio idóneo para la producción del resultado basta para imputar responsabilidad a una persona que inicia un incendio.

Pero más allá de cualquier cuestión probatoria, Hegel enfatiza que resulta indispensable atender no sólo a la dimensión objetiva de la voluntad sino también a la subjetiva. Y esto está a la base de la comprensión hegeliana del delito en relación con la imputación. Para que exista la comisión de un delito, el propósito del actor y su saber respecto de las circunstancias son tan determinantes como la producción del resultado materializado en el hecho. La acción del agente no es independiente de su saber y este saber es condición para la atribución de un hecho como suyo. De ahí que Hegel distinga acción (Handlung) de hecho (Tat) a fin de diferenciar el aspecto subjetivo, interior y consciente de la primera del carácter objetivo y exterior del segundo,

La finitud de la voluntad subjetiva en la inmediatez de la acción consiste inmediatamente en que para su actuar tiene un objeto exterior presupuesto acompañado de una multiplicidad de circunstancias. El hecho provoca un cambio en esta existencia previa y la voluntad tiene responsabilidad de él en la medida en que la existencia alterada lleva en sí el abstracto predicado de lo mío (GW 14.1, §115, p. 104).

Sólo cuando esto sucede, el sujeto encuentra satisfecho su derecho a determinarse en la acción al saber el hecho como suyo. Pero con ello se introduce el problema de la intención (Absicht) del agente, es decir, de cómo sus móviles se dirigen a un objetivo más general que le otorga al hecho su significado. 
En relación con ello, Hegel introduce la distinción entre propósito (Vorsatz) e intención (Absicht) que también es relevante para la comprensión del delito y su relación con la imputación. El propósito explica qué es lo que el agente hace de acuerdo con su saber acerca de las circunstancias, mientras que la intención da cuenta de por qué o para qué hace lo que hace:

Si alguien provoca un incendio, un homicidio, uno se pregunta: ¿Por qué cometió el homicidio? No por el homicidio mismo, sino que allí hubo un fin positivo, uno particular distinto de este contenido totalmente universal. En tanto homicidio, no es todavía el contenido propio del sujeto. Si dijéramos que cometió el homicidio por el placer de matar, el placer sería ya un contenido positivo del sujeto en cuanto tal. Entonces, el hecho es la satisfacción del querer del sujeto. Aquí la exterioridad se abre al contenido positivo que alcanza el sujeto con su acción (GW 26.2, §121, p. 878).

Por lo tanto, en términos más generales puede decirse que la intención presupone un desdoblamiento entre el hecho como algo universal (el homicidio o el incendio) y el móvil (por ejemplo, satisfacer la sed de venganza) como aquello que lleva al sujeto a fijarse un propósito para la realización de este fin (incendiar el granero donde duerme su enemigo) en el marco del cual se explica su acción y adquiere para él su significado.

Considerar al agente de una acción como ser racional implica asumir que tiene derecho a saber y querer aquello que hace cuando actúa, esto es, a saber y querer el contenido universal de su acción. A este derecho Hegel lo denomina "derecho de la subjetividad". Precisamente, los locos, los idiotas y los niños no son imputables por sus acciones en función de este derecho pues quizás sean conscientes de lo que están haciendo en el momento en que actúan, pero desconocen su contenido universal. Por ejemplo, la conciencia de encender una rama en un pastizal seco no implica ser consciente de estar provocando un incendio ni de sus posibles consecuencias; o bien, la conciencia de mantener bajo el agua a una persona, no implica ser consciente de estar provocando su muerte por asfixia. Frente a este "derecho de la subjetividad", Hegel reconoce como "derecho de la objetividad" considerar que la acción es "sabida y querida por el agente en cuanto éste es un ser pensante" (GW 26.1, \$120, p. 878). Por lo tanto, el "derecho de la subjetividad" completa el "derecho del saber" y presupone la capacidad del agente de una acción de poner lo universal como contenido de su voluntad. Esto último le permite conocer y querer el significado general del hecho que realiza tanto como sus implicancias objetivas, aun cuando no sea consciente de todas ellas al detalle.

Ahora bien, este "derecho de la subjetividad" o "derecho de la intención”, propio de la particularidad subjetiva, sólo tiene validez en tanto no entre en contradicción con su fundamento. De ahí que Hegel sostenga que una acción injusta no puede justificarse en función del bien que se intenta alcanzar con ella: “Mi particularidad, lo mismo que la de los otros, es un derecho sólo en la medida en que soy un ser libre. No puede por tanto afirmarse en contradicción con éste, su fundamento sustancial” (GW 14.1, §126, p. 111). Así, la libertad del agente tendría lugar sólo cuando el móvil de la acción fuese su estricta universalidad. Pero este fundamento se presenta en la esfera de la "Moralidad" de manera puramente formal como deber. 
Ciertamente, el imperativo categórico kantiano expresa la exigencia de universalidad a fin de determinar si el móvil de una acción se encuentra en la razón o en las inclinaciones. Al respecto, Hegel observa que no es posible derivar deberes particulares que inclinen la decisión del agente a partir de la pretensión kantiana de querer el deber por el deber mismo. Tampoco es posible hacerlo intentando universalizar la máxima que rige la acción sin caer en contradicción, pues una contradicción presupone ya la afirmación previa de un contenido determinado:

...que no haya ninguna propiedad no contiene por sí ninguna contradicción, como tampoco que este pueblo singular o esta familia no existan, o que en general no viva ningún hombre. Si, por el contrario, se admite y supone que la propiedad y la vida humana deben existir y ser respetadas, entonces cometer un robo o un asesinato es una contradicción (GW 14.1, §135, p. 118).

Como no es posible derivar de este mero formalismo ningún bien particular, la compresión del bien y su realización se juegan únicamente en la interioridad del sujeto, es decir, en su intención.

Pero afirmar que el bien de una acción depende esencialmente de la buena intención del agente acarrea una serie de consecuencias difícilmente aceptables, aunque propias de la abstracción que caracteriza a la concepción moral del mundo:

El robo, la cobardía, el asesinato, etcétera, en cuanto acciones, es decir, en cuanto realizados por una voluntad subjetiva, tienen inmediatamente la determinación de ser la satisfacción de una voluntad tal y son por lo tanto algo positivo. Para hacer de la acción algo bueno basta con reconocer este aspecto positivo como mi intención respecto de ella; este aspecto es lo esencial para determinar que la acción es buena porque en mi intención la reconozco como el bien (GW 14.1, §140, p. 127).

Se advierte, entonces, que concentrarse en la intención implica desplegar la tensión entre dos determinaciones de la voluntad presentes en el individuo que actúa. En este desdoblamiento se exhibe, según Hegel, el lado subjetivo de la contradicción, cuyo lado objetivo se expone con el delito en los términos del "Derecho abstracto". El agente es responsable de su acción precisamente porque como ser racional puede actuar mal, es decir, puede querer afirmar su particularidad frente a lo universal, aunque no tenga que hacerlo necesariamente:

El mal, por consiguiente, lo mismo que el bien, tiene su origen en la voluntad; y la voluntad en su concepto es tanto buena como mala. La voluntad natural es en sí la contradicción que consiste en diferenciarse de sí misma y ser por sí e interior (GW 26.1, \$139, p. 903).

Para Hegel, la insuficiencia de la perspectiva moral radica en hacer depender la naturaleza ética de la acción exclusivamente de la elevación a universalidad de la opinión subjetiva. La interioridad puesta en clave de fundamento se expresa como convicción subjetiva respecto de la acción, cuyo principio exige obrar de acuerdo a las propias convicciones sobre lo bueno y lo justo. No obstante, Hegel señala que, 
...de acuerdo al principio de justificación fundado en la convicción se sigue la consecuencia respecto del modo de actuar de los otros frente al mío, que ellos tienen pleno derecho de considerar de acuerdo con su creencia y convicción mi acción como un delito (GW 14.1, §140, p. 131).

Por dicha razón, si se persevera en esta perspectiva, resulta imposible que tenga lugar la existencia exterior del bien, esto es, que se realice aquello a lo que aspira quien obra según sus convicciones. El derecho de la voluntad subjetiva muestra así su limitación cuando es absolutizado desde la perspectiva moral. Y esto explica por qué para la comprensión hegeliana del delito resulta tan inconsistente desatender al derecho de la subjetividad como considerarlo criterio excluyente de imputación.

En consecuencia, "Derecho abstracto" y "Moralidad" constituyen sólo perspectivas de análisis unilaterales y abstractas de fenómenos y categorías que encuentran su realización concreta en la vida ética. De ahí que tanto lo jurídico como lo moral sólo encuentren un despliegue satisfactorio en el marco de la "Eticidad" donde se abordan las instituciones en que los individuos llevan adelante su vida afectiva, económica y política. La tesis decisiva de Hegel respecto del delito es que ni la perspectiva jurídica ni la moral tomadas cada una por su lado permiten explicar el fenómeno de manera acabada, debido a que ambas son determinaciones abstractas: al derecho le falta el momento de la subjetividad que, por el contrario, es lo único relevante para la moralidad. Sólo lo ético proporciona un fundamento tanto a lo jurídico como a lo moral y permite que se realicen efectivamente como ramas de un todo (GW 26.2, §141, p. 916).

En la esfera de la "Eticidad" es posible recuperar de manera complementaria tanto la perspectiva jurídica como la moral porque ambas son momentos, objetivo y subjetivo respectivamente, de la realización del bien en la vida ética que encuentra su culminación en el Estado moderno: "lo ético tiene un contenido fijo que es por sí necesario y una existencia que se eleva por encima de la opinión subjetiva y del capricho: las leyes e instituciones existentes en y para sí" (GW 14.1, \$144, p. 137). Pero estas leyes e instituciones no son para el agente ético algo extraño y ajeno a su voluntad, sino que cuando actúa conforme a ellas está en su propio elemento, siente confianza en su acción y orgullo por las instituciones que lo cobijan. Por esta razón, Hegel sostiene que sólo en el marco del derecho positivo vigente en un Estado el fenómeno del delito puede ser comprendido de un modo satisfactorio.

\section{El delito en el derecho positivo de la "Eticidad"}

Si bien Hegel tiene esbozos teóricos previos, como el escrito acerca del "Sistema de la eticidad" (1802/03) de la época de Jena, los desarrollos más extensos y consistentes respecto de la vida ética están en la tercera parte de la Filosofía del derecho. Para abordar el tratamiento hegeliano del delito en la "Eticidad" conviene tener presente cómo está definida esta esfera:

La eticidad es la idea de libertad como bien viviente que tiene en la autoconciencia su saber, su querer y, por medio de su actuar, su realidad efectiva (...) El concepto de libertad devenido mundo existente y naturaleza de la autoconciencia" (GW 14.1, §142, p. 137). 
En tal sentido, la "Eticidad" implica la unidad de dos dimensiones de la voluntad que se presentaban escindidas en las esferas discursivas que la anteceden. Por ello es posible satisfacer aquí tanto las exigencias de las determinaciones jurídicas abordadas en el "Derecho abstracto" en torno a la categoría de persona, como las propias del sujeto moral que actúa conforme a sus propias convicciones tratadas en la "Moralidad". En la vida ética se concilian las pretensiones normativas de ambas esferas en el derecho positivo vigente en un Estado. Únicamente con la existencia del Estado, las leyes regulan de manera consciente la vida institucional de la que participan los sujetos en calidad de ciudadanos. Y con ello, tanto el derecho de la objetividad como el de la subjetividad dejan de ser meros supuestos y devienen realidad efectiva. De ahí que Hegel sostenga que,

...la realidad objetiva del derecho consiste, en parte, en ser para la conciencia, en llegar a ser sabido; en parte, en tener el poder de la realidad y valer, y por tanto en llegar a ser sabido como lo universalmente válido (GW 14.1, §210, p. 175).

Si bien Hegel considera que una convivencia verdaderamente humana no es posible sin leyes, esto no significa que puedan deducirse a priori de la razón con el propósito de establecer un sistema jurídico. Ello implica rechazar de plano el proyecto de un sistema jurídico fundado en una concepción de la ley como mera universalización de la existencia humana, pues el universal abstracto que opera en la ley no puede realizar ni reemplazar la universalidad de la existencia. Antes bien, la racionalidad de un sistema jurídico comienza con su positividad, esto es, con la determinación del derecho como ley. Esto implica que,

...lo que el derecho es en sí está puesto en su existencia objetiva, es decir, determinado para la conciencia por medio del pensamiento y conocido como lo que es justo y tiene validez: es la ley. El derecho es por esta determinación derecho positivo en general (GW 14.1, §211, p. 175).

Por lo tanto, para que el derecho sea derecho positivo es menester que haya, entre otras cosas, actividad legislativa, publicidad de las leyes, existencia de un mundo institucional organizado por ellas y también de tribunal como órgano encargado de su aplicación. De ahí que, aunque el tratamiento hegeliano del "Derecho como ley" tenga lugar en la "Administración de justicia", es decir, en el segundo momento de la "Sociedad civil", la existencia del Estado y sus leyes ya está presupuesta pues de la positividad del derecho dependen tanto la sociedad civil con sus respectivas dinámicas como también la familia y su entramado de relaciones.

En la "Eticidad", entonces, tiene lugar el saber de la ley como determinación válida para la conciencia jurídica general de la comunidad. La vigencia de la ley expresa la íntima convicción de los sujetos de derecho acerca de que las normas no son algo ajeno y exterior a ellos, producto de algún tipo de imposición que se ven obligados a aceptar y cumplir, sino el fundamento y la condición de posibilidad de su propia existencia como personas (Kloc-Konkolowicz, 2019). En tal sentido, Hegel afirma:

En esta identidad de la voluntad universal y la particular coinciden por lo tanto deber y derecho; por medio de lo ético el hombre tiene derechos en la medida en que tiene deberes y deberes en la medida en que tiene derechos (GW 14.1, §155, p. 143). 
De ahí que cuando comienza el tratamiento del Estado Hegel vuelve sobre este tema y explica que "aquella identidad absoluta del deber y el derecho sólo tiene lugar también como identidad del contenido si éste es totalmente universal, es decir, si es el principio único del deber y del derecho, la libertad personal” (GW 14.1, §261, p. 209).

Por tanto, la libertad personal encuentra su realización allí donde se reconoce la validez universal de la categoría de persona y este reconocimiento se expresa en la relación sinalagmática entre deberes y derechos que tiene lugar entre los ciudadanos de un Estado. Actuar como ciudadano implica no sólo comportarse de acuerdo a las leyes vigentes en el Estado sino esperar que los otros también lo hagan. Mediante la generalización de expectativas de comportamiento tiene lugar una arquitectura institucional en la que los individuos pueden encauzar sus proyectos vitales y realizarse como personas. De ahí que sólo en la "Eticidad", donde la existencia del Estado permite ordenar las distintas esferas de vida en el marco del derecho positivo vigente, sea posible cumplir con el precepto del derecho formulado al comienzo del "Derecho abstracto", a saber: "Sé persona y respeta a los otros como personas" (GW 14.1, §36, p. 52).

En este contexto, el delito adquiere otro significado que permite completar la comprensión hegeliana del fenómeno y también entender como complementarios diversos aspectos ya considerados en las secciones previas. A diferencia de lo que ocurría con la violación del derecho en el marco del "Derecho Abstracto", con el derecho positivo vigente en un Estado es efectivamente posible la restitución o restauración del derecho cuando una ley ha sido quebrantada. Aquí la administración de justicia no queda librada al hacer contingente de los particulares en el ejercicio del castigo a través de las diversas formas de venganza, sino que existe un órgano gubernamental intersubjetivamente reconocido que representa el punto de vista de la voluntad universal. Se trata del tribunal que tiene la función de restituir la vigencia del derecho cuestionada con el delito (GW 14.1, §219, p. 182).

En efecto, en un estado de derecho la lesión de una norma con un acto delictivo no inaugura un círculo infinito de reparaciones contingentes a través del ejercicio recíproco de venganzas entre ciudadanos particulares, sino que un tribunal tiene la función de administrar justicia y el juez de aplicar la ley. Pero esta aplicación no está exenta de problemas y colisiones pues se trata de subsumir un caso singular bajo una ley universal. Y ello siempre lleva aparejado conflictos de interpretación. Hegel observa que, si no fuera así,

...la aplicación sería completamente maquinal y las máquinas podrían entonces ocupar el lugar del juez, el lugar de lo humano (...) El juez tiene que mediar entre las colisiones y decidir. No tener leyes y dejar el derecho librado al buen criterio es peor que las colisiones. En consecuencia, las leyes tienen que ser conocidas para poder estar determinadas; ellas provienen del pensamiento, por lo que pertenecen a la conciencia pensante (GW 26.1, §211, pp. 973-974).

Como el tribunal es un órgano que media entre la singularidad de los individuos y la universalidad abstracta de la ley, su proceder no puede ser inmediato ni privado, es decir, no puede quedar librado a la mera subjetividad de sus miembros ni del juez, sino que el derecho adquiere también aquí la determinación de ser público y demostrable (GW 26.2, §124, p. 984). De ahí que tanto las leyes como los fallos y procedimientos judiciales deban estar debidamente fundamentados y 
también publicados. Ambas cláusulas, en la medida en que someten a control social el accionar del sistema jurídico, contribuyen a disminuir el grado de arbitrariedad que conlleva necesariamente la aplicación de la ley, es decir, la subsunción de un caso particular bajo una regla general. La posibilidad de dicho control se funda en la constitución discursiva de la conciencia jurídica general y en su capacidad reflexiva para interpretar el significado de las normas que están en juego dentro del sistema jurídico mismo. Desde luego, para ello es esencial que las leyes vigentes estén reunidas en códigos y redactadas con claridad:

Cada código tiene que contener determinaciones simples. Cuando el contenido del derecho es malo y la cosa retorcida, entonces, por supuesto definitio est periculosa; pero si el contenido es el derecho en y para sí, entonces tampoco la explicación es peligrosa (GW 26.2, §216, p. 977).

Como se evidencia en estas últimas consideraciones, el derecho de la subjetividad, que en la "Moralidad" sólo tenía relación con la conciencia del sujeto respecto de su acto, encuentra en la "Eticidad" su culminación. Los ciudadanos tienen derecho a conocer y comprender tanto las leyes como los procedimientos jurídicos a los cuales se someten.

En consecuencia, la administración de justicia en la "Sociedad civil" queda legitimada como institucionalización de la conciencia jurídica general que presupone el reconocimiento recíproco entre individuos que han aprendido -como pueblo a través de una historia de luchas y como particulares mediante la educación familiar- a comprender al otro como un momento positivo esencial en la constitución de su propia identidad. La objetivación de esta conciencia tiene lugar tanto en las leyes vigentes como en las instituciones normativamente reguladas. Y esto implica una resignificación de la teoría del delito expuesta en el “Derecho abstracto". Bajo estos presupuestos el quebrantamiento de una norma con una acción delictiva no sólo constituye una negación de la persona en cuanto subjetividad infinita (situación que conduce a la venganza como castigo) sino que afecta a la sociedad en su conjunto. Quien viola una norma defrauda las expectativas sociales depositadas en él, pero también las expectativas generales de la sociedad respecto del cumplimiento de las normas. Aunque el delito recaiga sobre la persona de la víctima que recibe la violencia del acto criminal, también comporta al mismo tiempo una desestabilización de las estructuras de expectativas en función de las cuales están organizadas las instituciones sociales (Jakobs, 2008).

Por esta razón, el delito es concebido en la esfera de la "Eticidad" también desde el punto de vista de su peligrosidad social. Dicha peligrosidad no radica tanto en la violencia del acto criminal como en su capacidad para poner en tela de juicio la vigencia de las normas y las expectativas sociales depositadas en ellas. En función de estas expectativas los individuos no sólo se orientan para satisfacer sus necesidades, sino que además diseñan planes que le confieren sentido a sus vidas. De ahí que Hegel afirme lo siguiente:

El hecho de que en un miembro de la sociedad sean lesionados todos los demás cambia la naturaleza del delito no según su concepto sino según el lado de su existencia exterior, la lesión afecta ahora la representación y la conciencia de la sociedad civil, no sólo la existencia del inmediatamente lesionado (GW 14.1, §218, p. 182). 
Y en sus lecciones berlinesas de 1818/19 profundiza este aspecto desde la perspectiva de la reacción que genera la acción delictiva:

...contra el delito se erige no la parte lesionada sino lo universal lesionado y se hace cargo de su prosecución y sanción, la cual ha dejado de ser una retribución subjetiva a través de la venganza y se transforma en una reconciliación del derecho consigo mismo, como ley universal y válida para el delincuente mismo y por eso protectora; se transforma en pena (GW 26.1, §110, p. 305).

Por lo tanto, en el contexto del derecho positivo vigente en un Estado expuesto en la esfera de la "Eticidad", la sanción penal no debe estar enfocada únicamente en el ejercicio de la retribución. La medida de la pena ha de incorporar, además, la variable de la peligrosidad social que acarrea el delito. De lo contrario, si con la determinación de la pena se atiende sólo al valor, en cuanto universalidad interna que permite equiparar las acciones de delinquir y castigar, es posible que la restitución del derecho lesionado con la acción delictiva no tenga lugar a través del castigo y las expectativas sociales depositadas en la vigencia de la norma queden irremediablemente defraudadas. Esta es la razón por la que, según Hegel, las penas suelen ser más duras en casos de conspiración o de reincidencia:

\begin{abstract}
Quien trama un complot ha superado su temor al crimen y ha fortalecido su voluntad con la de otros hombres (que lo ayudan como medio), y la acción es la acción de una voluntad más intensa. Lo mismo ocurre cuando la voluntad ha traspasado varios grados. Así, la reincidencia en el delito muestra que el delito, el mal, se ha vuelto universal, permanente, habitual; $y$ todo esto hay que tenerlo en cuenta al momento de castigar (GW 26.1, §114, p. 130).
\end{abstract}

No obstante, tampoco puede suceder que la peligrosidad social que conlleva el delito sea el único criterio para la determinación de la pena. Esto implicaría incurrir en un error dado que "la peligrosidad es sólo un momento, y un momento inadecuado, porque es representado como si fuera a castigarse en el delito una posibilidad ajena a él” (GW 26.1, §114, p. 131). Por tanto, no atender a la peligrosidad social del delito es tan errado como centrarse exclusivamente en ella para determinar la medida de la pena.

Dado que la moderna sociedad civil se funda en la posibilidad de un intercambio pacífico de bienes para la mutua satisfacción de las necesidades y el desarrollo de planes de vida, la figura jurídica del contrato asume un rol determinante pues fija a nivel formal el momento del reconocimiento recíproco de los individuos como propietarios. Con esta operación simbólica se instala en la conciencia jurídica general de la sociedad la validez universal de la categoría de persona. En este marco, la irrupción del delito atenta contra esta validez y afecta el principio organizativo de la sociedad civil que posibilita la libertad de todos. Por ello, resulta necesario que las acciones delictivas tengan persecución penal y no queden impunes; de lo contrario, valdrían como acciones justas y el derecho como tal dejaría de cumplir su función orientadora del contacto social. Para que esto no suceda y se restituya la validez del derecho tras la irrupción del delito es menester que la medida de la pena incorpore el elemento cualitativo referido a la peligrosidad social. Con ello, el derecho fijado como tal en los códigos positivos se introduce en la temporalidad fluida de las representaciones sociales acerca de la solidez que ostentan las instituciones vigentes para la conciencia general de la sociedad. 
La línea de razonamiento que conduce la reflexión hegeliana parece ser la siguiente. El delito en tanto acción de un ser racional puede ser interpretado como un modelo alternativo de conducta que no sólo tiene un aspecto negativo como quebrantamiento de la norma vigente sino también uno propositivo como ejemplo a seguir. Frente al modelo alternativo de acción que propone el delincuente se encuentran su persecución penal, la condena y la ejecución de la pena como contraejemplo positivo que exhibe la nulidad de la acción delictiva y restablece la confianza en el imperio de la ley. Por ello, Hegel señala que cuanto más segura de sí misma se sienta una sociedad, cuanto más afianzado esté en la conciencia jurídica general el valor universal de la persona como destinatario de derechos y obligaciones, menos severas serán las penas dado que la peligrosidad social del delito será mucho menor. Por el contrario, una sensación general de inestabilidad institucional contribuye al endurecimiento del castigo que suele asumir funciones ejemplares (GW 14.1). De este modo, el grado de severidad de las penas expresa el juicio de una sociedad respecto de la solidez institucional de su propia estructura normativa y la fortaleza o debilidad de las expectativas depositadas en el cumplimiento de las normas: "Por eso con el desarrollo de la sociedad, las penas se hacen más moderadas, porque la Constitución resulta menos lesionada por el quebrantamiento individual del derecho" (GW 26.1, §108, p. 305). Por el contrario, la implementación de medidas coercitivas y el endurecimiento de las penas son signos que revelan estructuras sociales poco desarrolladas o bien un proceso de involución social. La tesis hegeliana respecto de la severidad de las penas es que allí donde la autoconciencia se reconoce a sí misma en las leyes del Estado, la coerción en todas sus formas tiende a devenir superflua.

\section{Conclusión}

Según la comprensión hegeliana, el delito tiene lugar en el plano de la exterioridad de la voluntad y atenta contra la universalidad de la persona. En términos objetivos se trata de una acción cuya estructura es análoga a la de un juicio contradictorio en la medida en que niega aquello que afirma, a saber: el valor de la persona. El delito es una exteriorización de la voluntad que, al suprimir una existencia exterior de la voluntad, niega sus propias condiciones de posibilidad. Pero como sólo hay delito si tanto el autor como de la víctima son considerados personas, es decir, destinatarios de derechos y obligaciones, esta acción se manifiesta como nula, pues conlleva la pretensión de eliminar el derecho cuya existencia misma presupone y confirma. En la pena se expresa dicha nulidad al restituir la validez del derecho retribuyendo al autor la violencia que ejerció sobre la víctima con su acción criminal.

Sin embargo, no basta con que un acto sea el presupuesto necesario para la producción de un resultado que causa una lesión en la víctima para considerar a su agente autor de un delito, dado que el estado de conocimiento del actor respecto de su acción no sólo determina su grado de responsabilidad respecto del hecho sino también el significado de la acción misma. Por tanto, no hay delito si el autor desconoce por completo lo que está haciendo o bien lo sabe, pero el resultado no responde en absoluto a su propósito conforme a las circunstancias. En tal sentido, en términos subjetivos, el delito es una acción que ha de poder ser atribuida a un actor y para que esto suceda es menester que el agente sea consciente de su acto y tenga el propósito de llevarlo a cabo con un medio idóneo de acuerdo a las circunstancias. Sólo así el acto le puede ser imputado. Al respecto, el derecho de la subjetividad en relación con la imputación implica que las leyes y procedimientos judiciales no sólo se presuman conocidos, sino que se den a conocer con concisión y sencillez a los ciudadanos no sólo para que puedan cumplir con las 
normativas vigentes sino también ejercer un control racional sobre los procesos de construcción de la voluntad jurídica.

Dado que la libertad personal encuentra su realización plena en el marco de las leyes e instituciones de un Estado que reconoce la validez universal de la persona, el delito en cuanto quebrantamiento de una norma vigente afecta no sólo a la víctima sino a la sociedad en su conjunto. En el marco del derecho positivo, el delito implica cierta peligrosidad social que no está tanto en la violencia del acto criminal como en su capacidad para defraudar y poner en tela de juicio las expectativas sociales depositadas en el cumplimiento de las normas vigentes. Por ello, esta dimensión debe ser incorporada en la determinación de la pena a los fines de restituir la confianza de la ciudadanía en la vigencia de las normas y que el derecho sea restablecido en su validez.

\section{Referencias}

Hegel, G.W.F. (SS) (1967) System der Sittlichkeit. Georg Lasson (Ed.) Felix Meiner.

Hegel, G.W.F. (GW 14.1) (2009). Grundlinien der Philosophie des Rechts [1820]. In K. Grotsch \& E. WeisserLohmann (Eds.). Gesammelte Werke. Vol. 14.1. Felix Meiner

Hegel, G.W.F. (GW 26.1) (2009). Vorlesungen über die Philosophie des Rechts. Nachschriften zu den Kollegien der Jahre 1817/18, 1818/19 und 1819/20. In K. Grotsch \& E. Weisser-Lohmann (Eds.). Gesammelte Werke. Vol. 26.1 Felix Meiner

Hegel, G.W.F. (GW 26.2) (2009). Vorlesungen über die Philosophie des Rechts. Nachschriften zu den Kollegien der Jahre 1821/22 und 1822/23. In K. Grotsch \& E. Weisser-Lohmann (Eds.). Gesammelte Werke. Vol. 26.2 Felix Meiner

Hegel, G.W.F. (WL) (1970). Wissenschaft der Logik. In E. Moldenhauer y K. Michel (Eds.). Theorie Werkausgabe. Vol. 5-6. Suhrkamp.

Jakobs, G. (2008). Norm, Person, Gesellschaft. Vorüberlegungen zu einer Rechtsphilosophie. Dunker \& Humblot Kloc-Konkolowicz, J. (2019). Ethos und Sittilchkeit. Hegels kleine Philosophie der Gewonheit. En T. S. Hoffmann \& H. Neumann (Eds.). Hegel und das Projekt einer philosophischen Enzyklopadie. (pp. 259-270). Duncker \& Humblot

Luhmann, N. (1995). Das Recht der Gesellschaft. Suhrkamp

Metzger, E. (1949). Strafrecht. Ein Lehrbuch. Duncker et Humblot

Ormeño Karzulovic, J. (2020). Las condiciones formales de la persecución individual del Bien: la moralidad subjetiva en las Grundlinien der Philosophie des Rechts de Hegel, §§ 119-128. Mutatis Mutandis: Revista Internacional de Filosofía, 1(15), 51-65. https://zenodo.org/record/5001985

Simester, A. P., \& Von Hirsch, A. (2011). Crimes, Harms, and Wrongs. On the Principles of Criminalisation. Hart Publishing.

\section{AUTOR}

Esteban Mizrahi. Doctor en filosofía por la Universidad del Salvador con estudios posdoctorales en la Universidad de Bonn. Licenciado en filosofía por la Universidad de Buenos Aires con estudios de especialización en ciencia política y filosofía práctica en la Universidad de Münster. Profesor titular de filosofía y filosofía del derecho en la Universidad Nacional de La Matanza, Argentina. 